East African Medical Journal Vol. 81 No. 1 January 2004

DEMAND FOR ORTHODONTIC TREATMENT AMONG 9-18 YEAR-OLDS SEEKING DENTAL CARE IN DAR-ES-SALAAM, TANZANIA

E.A. Mugonzibwa, DDS, Assistant Lecturer, Department of Preventive and Community Dentistry, Faculty of Dentistry, Muhimbili University College of Health Sciences, Dar es Salaam, Tanzania, A.M. Kuijpers-Jagtman, DDS, PhD, Department of Orthodontics and Oral Biology, University Medical Center, Nijmegen, the Netherlands, M. A. van 't Hof, PhD, Department of Cariology and Preventive Dentistry, University Medical Center, Nijmegen, the Netherlands, E.N. Kikwilu, DDs, M. Dent. Senior Lecturer, Department of Preventive and Community Dentistry, Faculty of Dentistry, Muhimbili University College of Health Sciences, Dar es Salaam, Tanzania

Request for reprints to: Prof. A.M. Kuijpers-Jagtman, DDS, PhD, Department of Orthodontics and Oral Biology, University Medical Center, University of Nijmegen, P.O. Box 9101, 6500 HB Nijmegen, the Netherlands.

\title{
DEMAND FOR ORTHODONTIC TREATMENT AMONG 9-18 YEAR-OLDS SEEKING DENTAL CARE IN DAR-ES-SALAAM, TANZANIA
}

\author{
E.A. MUGONZIBWA, A.M. KUIJPERS-JAGTMAN, M.A. VAN 'T HOF \\ and E.N. KIKWILU
}

\begin{abstract}
Objective: To investigate the demand for orthodontic treatment among 9-18 olds seeking dental care in Dar-es-Salaam, Tanzania.

Design: Case-control, interview and clinical study.

Settings: Children seeking dental care.

Main outcome measures: Demand for orthodontic treatment.

Results: Most of the children $(85 \%)$ in the case group attended the dental clinic because of crowding. Aesthetic impairment (AC grades 8-10) and severe malocclusions (DHC grades 4-5) were higher in cases than in controls being 47 and $5 \%$; and 67 and $18 \%$, respectively ( $\mathbf{p}<0.0001)$. Absolute need (combined AC grade 8-10 and DHC 4-5) was found in $29 \%$ of the cases and $5 \%$ of the controls $(p<0.0001)$. A relative probability for a child with absolute need to seek orthodontic treatment was 7.9 higher $(95 \%)$ CI for $O R=(5,13)$, compared to a child without an absolute need for orthodontic treatment. The most prevalent severe occlusal feature placing cases in the highest need category was crowding $(\mathbf{7 4 \%})$. For the cases, it was mainly a mother $(\mathbf{4 5 \%})$ who first recognized the problem in the family, and tooth extraction (62\%) was the most common expected mode of treatment. Most parents $(\mathbf{9 6 \%})$ were prepared to pay for their children's orthodontic treatment.

Conclusion: Most children in the case group had come to the clinic due to crowding. Ectopic canines were the driving factor for children and parents to seek orthodontic care. Further studies are recommended to map the demand for orthodontic treatment in the Tanzanian rural settings.
\end{abstract}

\section{INTRODUCTION}

The occurrence of malocclusion in Tanzanian children and adults has been reported in few studies(15) with prevalence of various occlusal irregularities ranging from $0-35 \%$, but the scope of demand for treatment has not been investigated. Although community based descriptive studies on the prevalence of occlusal characteristics and anomalies in Tanzania have been conducted(15), one should not only consider the prevalence of disorders, but equally important the demand for treatment shown by the affected individuals and/or their parents(6). Decisions about orthodontic treatment are generally made in childhood and an important aspect of the treatment is improvement of dental aesthetics to enhance the well-being of the individual rather than health or function(7-9). Not all individuals with malocclusion, even those with extreme handicapping malocclusions or anatomic deviations from the normal, seek orthodontic treatment. While some individuals may not recognise that they have a problem due to various reasons including young age, others feel that they can not afford or obtain orthodontic treatment. Both the perceived need and demand for orthodontic treatment vary with social and cultural conditions $(7,10)$. Utilization of health services is a matter of concern not only to the providers but also to the planners of health care delivery. Without a satisfactory estimate of the need and demand for orthodontic treatment, it is difficult to organize even a minimum orthodontic service both from human and financial resources point of view. The orthodontic treatment demand besides providing information on work-load, is of interest for public health programmes, clinical treatment, screening for treatment priority and resource planning(11).

Orthodontics is different from other dental specialties by different biological, psychological and 
cultural needs of individuals with occlusal irregularities. This is primarily due to the fact that orthodontics deal with disharmonic growth patterns and morphological deviations and not diseases(12). Therefore, orthodontic treatment is almost always elective and the patient should have an important say whether or not he/she will undergo treatment. Thus, the objectives of the present study was to investigate the demand for orthodontic treatment based on children's opinion on dental aesthetics of their own dentition, and demand related to dental health component (DHC) of the index of orthodontic treatment need (IOTN) among children seeking dental care in Dar-es-Salaam, Tanzania.

\section{MATERIALS AND METHODS}

Subjects: The present study had a case-control design involving Tanzanian Bantu children who were seeking oral health care in the months of June and December between 1999 and 2002 at Muhimbili National Hospital (MNH) paedodontic clinic in the dental school in the city of Dares-Salaam. All children aged 9-18 years who attended the clinic during the study period and who were willing to participate in the study were included. Children whose main complaint were interpreted by the investigator (EAM) as an orthodontic problem were allocated to the case group. The control group included all other children attending the dental clinic for non-orthodontic reasons who matched with the children in the case group for age, gender and tooth emergence stage of the permanent dentition. The distribution of the study subjects is shown in Table 1 .

Methods: For both cases and controls a structured interview and clinical forms were developed to collect the children's demographic data; parents education and occupation; estimation of the family's socio-economic status [SES] as low, average or high; location of residence in the Dar es Salaam city; and the main complaint of the child. For the children in the case group questions related to demand for orthodontic treatment were asked which included: who first recognized the problem in the family (Self, Mum, Daddy, Sibling, Peers, Relatives, Teacher); where did the family get information about orthodontic treatment; which type of treatment did the family expect from the clinic; and whether parents were prepared to pay about 55 Euro for orthodontic treatment. The interviews and clinical examinations were conducted in the conventional dental chair at the MNH Paedodontic clinic.

Clinical objective orthodontic assessment was made by investigator EAM using the index of orthodontic treatment need $(\mathrm{IOTN})(8,13,14)$. The index has two components: the Aesthetic Component (AC) and the Dental Health Component (DHC). To facilitate the recording a DHC ruler was used. The children also assessed their own dental aesthetic impairment using the scale of 10 intra-oral photographs of AC of the IOTN.

Molar occlusion according to Angle's classification was determined per side and recorded according to Bjork et al.(15) with slight modifications. Neutral occlusion (Class I) was registered when the mesio-buccal cusp of the maxillary first permanent molar occluded in the mesio-buccal groove of the mandibular first permanent molar. Distal (Class II) or mesial (Class III) occlusion were recorded when there was a deviation of at least one half a cusp width distally or mesially. Angle's class for the child was defined as class II if both sides were class II or III, respectively, otherwise it was considered to be Class I.

Forced bite was recorded as present when there was a mandibular shift or deflection in an anterior, posterior and/ or lateral direction, as a result of a premature contact occurring when the mandible is in centric relation. Thorough methodology training for IOTN measurements for the investigator (EAM) was done prior to the data collection at both the University of Manchester (United Kingdom) and University of Nijmegen (the Netherlands). Intra-examiner consistency of investigator EAM for the IOTN was studied using double determinations from 42 children within an interval of 21 days and expressed as Kappa reliability coefficient $(16,17)$.

The data were entered and analysed using SPSS statistical package (18). Chi-square and t-tests analyses were used to test various differences between sub-groups.

\section{RESULTS}

The intra-observer agreement (Kappa value) was 0.68 for the forced bite and 0.84 for Angle's classification. The duplicate measurement error for AC was 0.31 scale points and for the DHC of the IOTN 0.24 (Dahlberg). The reliability coefficients (Pearson correlations) were 0.99 and 0.95 for $\mathrm{AC}$ and $\mathrm{DHC}$, respectively.

Table 2 shows education and employment status of the children's parents. While 57 to $58 \%$ of the fathers had secondary education, 59 to $60 \%$ of the mothers had primary education and below. The percentage of parents with University education was $16 \%$ among fathers and 6 to $7 \%$ among the mothers. Most of the fathers $95 \%$ and $60 \%$ of the mothers had a regular job. The child's estimation of the family's socio-economic status [SES] showed that most children both in the case $(82 \%)$ and control $(77 \%)$ groups came from families with average to high social-economic status. With regard to district of residence in the City of Dar-es-Salaam, most study subjects resided in Kinondoni (49-50\%), followed by Ilala (33\%), Temeke (15\%) and elsewhere (2-3\%).

Neutral occlusion (Angle's Class I) was the most common among the children occurring in $90 \%$ of the cases and $91 \%$ of the controls respectively. Mesial molar occlusion (Angle's Class III) was rare in both the case and control groups prevailing in about $2 \%$ of the children.

About $40 \%$ of the children in the case group had forced bite whereas in the control group it occurred in about $21 \%$ of the children $(\mathrm{p}<0.0001)$. 
Figure 1

Table 1

Distribution of study subjects according to age and gender

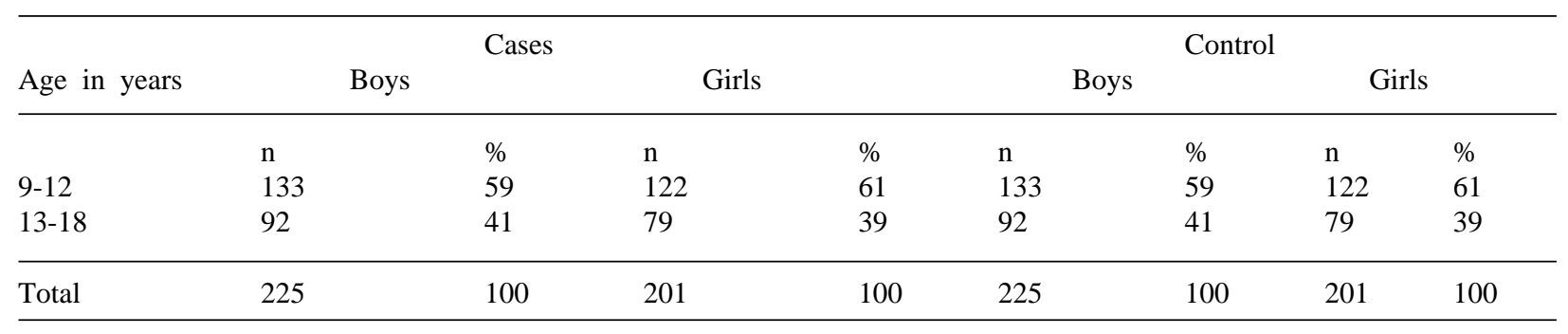


Table 2

The respondents' parents characteristics

\begin{tabular}{|c|c|c|c|c|c|}
\hline \multicolumn{6}{|l|}{ Parents' educational status } \\
\hline & \multicolumn{2}{|c|}{ Father } & \multicolumn{3}{|c|}{ Mothers } \\
\hline & Cases \% & Control \% & Cases ? & Control & $\%$ \\
\hline Primary education and below & 27 & 26 & 60 & & 59 \\
\hline Secondary education & 57 & 58 & 34 & & 34 \\
\hline University education & 16 & 16 & 6 & & 7 \\
\hline \multicolumn{6}{|l|}{ Parents' employment status } \\
\hline & \multicolumn{2}{|c|}{ Father } & \multicolumn{3}{|c|}{ Mothers } \\
\hline & Cases \% & Control \% & Cases o & Control & $\%$ \\
\hline Peasant and home job & 4.9 & 4.7 & 39.7 & & 36.4 \\
\hline Trader / Business & 32.6 & 33.3 & 24.9 & & 25.1 \\
\hline Employed & 62.0 & 61.5 & 35.4 & & 38.5 \\
\hline Unknown & 0.5 & 0.5 & 0 & & 0 \\
\hline
\end{tabular}

\section{Table 3}

Percentage and 95\% confidence intervals of the cases' and controls' clinical grades for Aesthetic Component (AC) and Dental Health Component

(DHC) of the IOTN

\begin{tabular}{|c|c|c|c|c|c|c|c|}
\hline \multicolumn{3}{|c|}{$\begin{array}{l}\text { Aesthetic Component (AC) } \\
\text { AC grades Treatment need }\end{array}$} & \multicolumn{3}{|c|}{ Cases $(n=426)$} & \multicolumn{2}{|c|}{ Controls $(n=426)$} \\
\hline & & $\mathrm{n}$ & $\%$ & $95 \% \mathrm{CI}$ & $\mathrm{n}$ & $\%$ & $95 \% \mathrm{CI}$ \\
\hline $1-4$ & $\begin{array}{l}\text { No/slight need for } \\
\text { treatment }\end{array}$ & 9 & 2.0 & $(1,4)$ & 216 & 58.9 & $(46,56)$ \\
\hline $5-7$ & $\begin{array}{l}\text { Moderate/borderline } \\
\text { need for treatment }\end{array}$ & 216 & 50.7 & $(46,56)$ & 154 & 36.2 & $(32,41)$ \\
\hline $8-10$ & $\begin{array}{l}\text { Need for orthodontic } \\
\text { treatment* }\end{array}$ & 201 & 47.2 & $(42,52)$ & 21 & 4.9 & $(3,7)$ \\
\hline \multicolumn{8}{|c|}{$\begin{array}{l}\text { Dental Health Component (DHC) } \\
\text { DHC grades }\end{array}$} \\
\hline & & $\mathrm{n}$ & $\%$ & $95 \% \mathrm{CI}$ & $\mathrm{n}$ & $\%$ & $95 \% \mathrm{CI}$ \\
\hline 1. & No need for treatment & 0 & 0 & $(0,1)$ & 172 & 40.4 & $(36,45)$ \\
\hline 2. & $\begin{array}{l}\text { Little need for } \\
\text { treatment }\end{array}$ & 0 & 0 & $(0,1)$ & 43 & 10.1 & $(7,13)$ \\
\hline 3. & $\begin{array}{l}\text { Borderline need for } \\
\text { treatment }\end{array}$ & 140 & 32.9 & $(28,38)$ & 133 & 31.2 & $(27,36)$ \\
\hline 4. & Need for treatment* & 263 & 61.7 & $(57,66)$ & 76 & 17.8 & $(14,22)$ \\
\hline 5. & Need for treatment* & 23 & 5.4 & $(3,8)$ & 2 & 0.5 & $(0,2)$ \\
\hline
\end{tabular}

$\cdot \mathrm{P}<0.0001$

Table 4

Percentages and 95\% confidence intervals (CI) of need for orthodontic treatment according to DHC subcategories in children with great need of orthodontic treatment (DHC grades 4-5)among cases and controls

\begin{tabular}{cllllll}
\hline $\begin{array}{c}\text { DHC } \\
\text { subcategory }\end{array}$ & \multicolumn{2}{c}{ Cases (n=286) } & \multicolumn{3}{c}{ Control $(\mathrm{n}=78)$} \\
\hline & $\mathrm{N}$ & $\%$ & $95 \% \mathrm{CI}$ & $\mathrm{n}$ & $\%$ & $95 \%$ CI \\
$\mathrm{a}$ & 41 & 14.3 & $(10,18)$ & 8 & 10.3 & $(5,19)$ \\
$\mathrm{b}$ & 6 & 2.1 & $(1,4)$ & 1 & 1.3 & $(0,1)$ \\
$\mathrm{c}$ & 1 & 0.7 & $(0,2)$ & 50 & 64.1 & $(54,75)$ \\
$\mathrm{d}$ & 211 & 73.8 & $(69,79)$ & 5 & 6.4 & $(2,14)$ \\
$\mathrm{e}$ & 11 & 3.8 & $(2,7)$ & 10 & 12.8 & $(6,22)$ \\
$\mathrm{i}$ & 16 & 5.6 & $(3,8)$ & 2 & 2.6 & $(0,9)$ \\
$\mathrm{m}$ & 0 & 0 & $(0,1)$ & 2 & 2.6 & $(0,5)$ \\
\hline
\end{tabular}

$\mathrm{a}=$ Increased overjet, $\mathrm{b}=$ Reverse overjet, $\mathrm{c}=$ Anterior/posterior crossbite

$\mathrm{d}=$ Contact point displacement, $\mathrm{e}=$ Open bite, $\mathrm{i}=$ Impeded eruption of teeth

$\mathrm{m}=$ Reverse overjet with recorded masticatory and speech difficulties 
Table 5

Responses to relevant questions on demand for orthodontic treatment among children in the case group $(n=426)$

\begin{tabular}{|c|c|c|}
\hline Who recognized the children's problem for the first time? & $\mathbf{n}$ & $\%$ \\
\hline Mother & 193 & 45.3 \\
\hline Child himself/herself & 90 & 21.1 \\
\hline Father & 78 & 18.3 \\
\hline Teacher & 23 & 5.4 \\
\hline Dentist & 17 & 4.0 \\
\hline Others & 25 & 5.9 \\
\hline \multicolumn{3}{|l|}{ Mode of Treatment the child and parent expected: } \\
\hline Extraction & 266 & 62.4 \\
\hline Advice & 79 & 18.5 \\
\hline Orthodontic appliance & 75 & 17.6 \\
\hline Prosthesis & 6 & 1.4 \\
\hline \multicolumn{3}{|l|}{ Family's source of information about orthodontic treatment: } \\
\hline Advised by a dental clinician & 196 & 46.0 \\
\hline No source of information & 86 & 20.2 \\
\hline Another child in orthodontic treatment & 86 & 20.2 \\
\hline Advised by friends and relatives & 25 & 5.9 \\
\hline Teacher/ Medical doctor & 9 & 2.1 \\
\hline \multicolumn{3}{|l|}{ Could parents pay about 55 Euro for treatment? } \\
\hline Yes & 407 & 95.5 \\
\hline No/Do not know & 19 & 4.4 \\
\hline
\end{tabular}

While most of the children in the case group came to the hospital because of crowding $(85.2 \%)$ followed by overjet $(11 \%)$, open bite $(3.5 \%)$ and one child because of missing tooth, all chlldren in the control group had come to the clinic because of pain. Percentage and $95 \%$ confidence intervals (CI) of need for orthodontic treatment according to the $\mathrm{AC}$ and $\mathrm{DHC}$ of the IOTN are presented in Table 3 . Only $2 \%$ of the children in the case group considered themselves to have no/slight need for treatment (AC of the IOTN) whereas $5 \%$ of the children in the control group regarded themselves to have great need for orthodontic treatment (AC grades 8-10). Aesthetic impairment (AC grades 8-10) among children in the case group was higher than in the control group being $47 \%$ and $5 \%$ respectively $(\mathrm{p}<0.0001)$. With regard to moderate/ borderline aesthetic impairment (AC grades 5-7), 72 and $74 \%$ of the children in the case group and control group scored themselves grades five and seven (Not in the table). Also $49 \%$ of the 47 children in the case group falling in the highest aesthetic impairment category (AC grades 8-10) scored themselves grade 8.

Clinically, all children demanding orthodontic care (case group) fell in grades three to five of the DHC of the IOTN whereas $67 \%$ of the children were found with great need (DHC grades 4-5) being higher than $18 \%$ found in the Control group $(\mathrm{p}<0.0001)$.

When need for treatment based on AC (grade 8$10)$ and DHC (4-5) were combined, $29 \%$ of the children in case group and $5 \%$ of the controls had a great need for both aesthetic and dental health components (absolute need) for orthodontic treatment $(\mathrm{p}<0.0001)$. The relative probability for a child with absolute need to seek orthodontic treatment was 7.9 higher $(95 \% \mathrm{CI}$ for $\mathrm{OR}=$ 5,13 ), compared to children without an absolute treatment need.

The percentage and $95 \%$ confidence intervals (CI) of need for orthodontic treatment according to DHC sub-categories in children with great need of orthodontic treatment (DHC grades 4-5) are presented in Table 4. The most prevalent severe occlusal feature placing the children demanding orthodontic care (case group) in this need category was contact point displacement (74\%). This is in contrast to the control group where the majority of the children with great need for treatment had an anterior/posterior crossbite.

Responses to questions relevant to demand for orthodontic treatment for the children demanding orthodontic care (case group) are shown in Table 5. Mostly the mother (45\%) was the first person in the family to recognise the problem followed by the child $(21 \%)$ and father (18\%). Tooth extraction (62\%) was the most common expected mode of treatment by both the child and the parent followed by advice (18\%) and orthodontic appliance (18\%). In $46 \%$ of the study subjects, it was reported that the family got information about orthodontic treatment from a dental clinician or seeing another child undergoing treatment (20\%). Almost all parents were prepared to pay about fifty five Euro for their children's orthodontic treatment (96\%). 


\section{DISCUSSION}

In this case-control study, demand for orthodontic treatment in a hospital-based sample of children aged 9-18 years seeking dental care from the Muhibili district hospital Paedodontic clinic was investigated. The MNH Paedodontic clinic receives children from a wide range of social background in the city of Dares-Salaam, Tanzania. Generally, all children with orthodontic problems in Dar-es-Salaam are referred to the clinic, a few are referred to clinics outside Dares-Salaam. All children who were requested did accept to participate in the study. The sample in the present study may not be representative for the whole Tanzanian children population of the studied ages, but rather gives an overview of the children demanding orthodontic care in the Tanzanian urban settings. Although half of the children came from the high socio-economic status Kinondoni district, the district of residence was not associated with need categories for orthodontic treatment.

A high prevalence of neutral occlusion both in case and control groups were recorded being in agreement with earlier reports on Tanzanian children and adults (2-4,19). Studies comparing African, African American and Caucasian children have also shown that the first two have sagittally less often distal occlusion and more often neutral(2,20-21) and mesial occlusions(20-21) than Caucasians. The present results probably confirm the basic structural differences in the sagittal skeletal relationship(22) between Tanzanian Bantu and Caucasian children.

The majority of the children in the case group ( $85 \%$ ) had come to the Paedodontic clinic because of crowding followed by overjet $(11 \%)$ and open bite (3.5\%). Horowitz et al.(23) investigating 10-12 yearold children and Ingervall and Hedegard(24), investigating 18 year-old males, found that the perception of irregular alignment and spacing was greater than the perception of overjets.

Aesthetic need (AC grades 8-10) for orthodontic treatment based on the children's own opinion was found in about half of the children seeking orthodontic care and in only $5 \%$ of the children in the control group. Most children in both the case (72\%) and control (74\%) group in the moderate/borderline aesthetic impairment (AC grades 5-7) category scored themselves grades five and seven suggesting that overjet was the children's main concern. With regard to the highest aesthetic impairment category (AC grades 8-10), about half of the $47 \%$ children in the case group scored themselves grade eight indicating that the ectopic canines were the driving factor for the children and parents to seek orthodontic consultation.

In both the case and control groups, more children had occlusal irregularities falling in the highest category of need for orthodontic treatment according to DHC (grades 4-5) than the AC impairment (grades 8-10). The results showed that the main severe occlusal feature which was responsible for allocation of children into the category of high objective clinical need (DHC 45) for orthodontic treatment was crowding. This finding is in complete agreement with $85 \%$ of the children among cases as they came to the dental clinic because of tooth displacement. Interestingly, borderline need cases and controls were about the same probably indicating that the category is real borderline and children who may ask for orthodontic treatment have an absolute need. Socio-economic status was not associated with objective need for orthodontic treatment.

More than sixty percent of the children demanding orthodontic care, expected tooth extraction as the common mode of treatment for their occlusal irregularity. In the control group all children had come to the clinic because of pain. This could be because the perceived need and the use of oral health services in Tanzania are heavily associated with relief of pain and discomfort (25-26) mainly due to caries pulp involvement (27), periodontal disease (28), and tooth extraction is the most common mode of treatment provided (29). Surprisingly, $18 \%$ of the children expected removable orthodontic appliance(s).

In most of the children demanding orthodontic care, occlusal irregularities were first recognized by the mother $(45.3 \%)$ as was also found in the study of Baldwin and Barnes (30). About $46 \%$ of the children demanding orthodontic care reported getting information about orthodontic treatment mainly from an oral health Clinician (Dental Officer, Assistant Dental Officer, Dental therapist). Shaw et al.(31) and Gosney(32) reported that dentist's advice appeared to be the major motivating factor for both children and parents in seeking orthodontic treatment. On the other hand, it has been suggested that greater availability of orthodontic treatment stimulates demand for orthodontic care $(7,33)$. In another study by Lindegard et al. (6), a close relationship between orthodontic treatment demand and personal orthodontic experiences of the parents were reported.

The majority (95\%) of the parents the children in the case group were prepared to pay for their children's orthodontic treatment, suggesting that even families with limited financial resources were willing to use them for correction of malocclusion, presumably because it is a major concern. However, most of them would afford paying if the total amount would be paid in more than one installment probably acknowledging that the most severe occlusal problems should be treated regardless of income levels. Nevertheless, the results could have been influenced by an urban nature of the population in our study which may not be representative of the whole Tanzanian population.

In conclusion, most children in the case group had come to the clinic due to crowding. Ectopic canines were the driving factor for children and parents to seek orthodontic care. Further studies are recommended to map the demand for orthodontic treatment in the Tanzanian rural settings. 


\section{ACKNOWLEDGEMENTS}

To all the staff of the Muhimbili National Hospital (MNH) Paedodontic clinic in the Dental School for their co-operation during data collection and to all the children and parents for their acceptance to participate in the study. The authors also wish to thank the WHO Collaborating Centre for Oral Health Care Planning and Future Scenarios for facilitating the funding and to Muhimbili University College of Health Sciences (MUCHS) for partial funding of the study.

\section{REFERENCES}

1. Kerosuo, H., Laine, T., Kerosuo, E., Ngasapa, D. and Honkala, E. Occlusion among a group of Tanzanian urban school children. Community Dent Oral Epidemiol. 1988; 16:306-309.

2. Kerosuo, H. Occlusion in the primary and early mixed dentition in a group of Tanzanian and Finnish children. $J$ .Dent .Child . 1990; 57:293-298.

3. Mugonzibwa, E.A., Mumghamba, E., Rugarabamu, P. and Kimaro, S. Occlusal and space characteristics among 12 year-old school children in Bukoba and Moshi, Tanzania. Afr. Dent. J. 1990; 4:6-10.

4. Mugonzibwa, E.A. Variation in occlusal and space characteristics in a series of 6 to 18 years old, in Ilala district, Tanzania. Afr. Dent. J. 1992; 6:17-22.

5. Mugonzibwa, E.A. Occlusion survey in a group of Tanzanian adults. Afr. Dent. J. 1993; 7:6-10.

6. Lindegard, B., Lindegard, L., Carlson, M. and Larsson, S. Need and demand for orthodontic treatment. Tandlaegebladet. 1971; 75:1198-1210.

7. Tulloch, J.F., Shaw, W.C., Underhill, C., et al. comparison of attitudes toward orthodontic treatment in British and American Communities. Amer. J.Orthod. 1984; 85:253259.

8. Brook, P.H. and Shaw, W.C. The development of an index of orthodontic treatment priority. Eur. J. Orthod. 1989; ll:309.

9. Shaw, W.C., O'Brien, K.D. and Richmond, S. Quality control in orthodontics: factors influencing the receipt of orthodontic treatment. Brit. Dent. J. 1991; 170:66-68.

10. Wheeler, T.T., McGorray, S.P., Yurkiewicz, L., et al. Orthodontic treatment demand and need in third and fourth grade school children. Amer. J. Orthod. Dentofacial. Orthop. 1994; 106:22-33.

11. Foster, T.D. The public health interest in assessment for orthodontic treatment. J. Public .health Dent. 1979; 39: 137-142.

12. Ter Heege G. Euroqual. Towards a quality system for European orthodontic professions. Amsterdam: IOS Press. 1997.

13. Richmond, S., O'Brien, K.D., Buchanan, I.B. and Burden, D.J. An introduction to occlusal indices. Manchester: Ortho-care (UK). 1992.

14. Evans, R, and Shaw, WC. Preliminary evaluation of an illustrated scale for rating dental attractiveness. Eur. J. Orthod. 1987; 9:314-318.

15. Bjork, A., Krebs, A. and Solow, B. A Method for epidemiological registration of malocclusion. Acta. Odontol. Scand. 1964; 22:27-41.

16. Cohen, J. A coefficient of agreement for nominal scales. Educ. Psych. Meas. 1960; 20:37-46.

17. Landis, J.R. and Koch, G.G. The measurement of observer agreement for categorical data. Biometrics. 1977; 33: 159-174.

18. SPSS Inc. 1990 The statistical package for the social sciences. SPSS; Chicago Illinois.

19. Kerosuo, H., Laine, T., Nyssonen, V. and Honkala, E. Occlusal characteristics among groups of Tanzanian and Finnish urban school children. Angle Orthod. 1991; 61: 49-56.

20. Lavelle, C.L.B. A study of multiracial malocclusions. Community Dent. Oral Epidemiol 1976; 4:38-41.

21. McLain, J.B. and Proffit, W.R. Oral health status in the United States: Prevalence of malocclusion. J. Dent. Educ. 1985; 49:386-396.

22. Enlow, D.H., Pfister, C., Richardson E. and Kuroda T. An analysis of Black and Caucasian craniofacial patterns. Angle Orthod 1982; 52:279-287.

23. Horowitz, H.S., Cohen, L.K. and Doyle, J. Occlusal relations in children in an optimally fluoridated community IV. Clinical and social-psychological findings. Angle Orthod. 1971; 41:189-201.

24. Ingervall, B. and Hedegard, B. Awareness of malocclusion and desire of orthodontic treatment in 18-year old Swedish men. Acta Odontol Scand. 1974; 32:93-101.

25. Van Palenstein Helderman, W.H. and Nathoo, Z.A.W. Dental Treatment Demands among patients in Tanzania. Community Dent. Oral Epid. 1990; 18:85-87.

26. Mosha, H.J. and Scheutz F. Perceived need and use of oral health services among adolescents and adults in Tanzania. Community Dent Oral Epidemiol 1993; 21:129-132.

27. Christensen, L.,Lembariti, B.S. and van Palenstein Helderman, W.H. Utilisation of dental services by factory workers in Morogoro. Tanz. Dent J. 1997; 8:10-12.

28. Gemba, P.M., Kydyalla, R. and van Palenstein, Helderman, W.H. Dental Treatment demands in two cities in Tanzania. Afr. Dent. J 1988; 2:38-43.

29. Matee, M.I. and Simon, E. Utilisation of Dental Services before and after the introduction of coast sharing. Int. Dent. J. 2000; 50:69-72.

30. Baldwin, D.C., Jr. and Barnes, M.L. Some psychosocial factors motivating orthodontic treatment . J. Dent. Res. 1965; 43:146-153.

31. Shaw, W.C., Grabe, M.J. and Jones, B.M. The expectations of orthodontic patients in South Wales and St. Louis, Missouri. Brit. J. Orthod. 1979; 6:203-205 .

32. Gosney, M.B. An investigation into some of the factors influencing the desire for orthodontic treatment. Brit. J. Orthod. 1986; 13:87-94.

33. Gravely, J.F. A study of need and demand for orthodontic treatment in two contrasting National Health Service regions. Brit. J. Orthod. 1990; 17:287-292. 